\title{
Análise tarifária em instalações elevatórias de água - cenários para mitigação do impacto econômico das faturas de energia elétrica
}

Fee analysis in water lift stations - scenarios for the mitigation of electric services bills economic impact

\author{
D. R. Steffens ; ; E. S. Silva; L.A. de O. Rocha; P. R. Wander \\ Escola Politécnica/PPGEM, Unisinos, 93.022-750, São Leopoldo-RS, Brasil
}

daniel_actia@yahoo.com.br

\begin{abstract}
Este artigo tem por objetivo avaliar a situação econômico-operacional de uma estação elevatória de água bruta, que atende a dois grandes municípios do sul do Brasil, frente ao estabelecido na resolução normativa $\mathrm{n}^{\circ}$ 414, de 09 de setembro de 2010, da ANEEL. A instalação é composta de cinco conjuntos motobombas que são acionados de acordo com as sazonalidades do consumo de água tratada no sistema de abastecimento. Na configuração de projeto, dois conjuntos motobombas eram reservas operacionais e, portanto, até três equipamentos eram acionados de maneira paralela. A partir de janeiro de 2016, por uma necessidade operacional de maior vazão disponibilizada ao sistema de abastecimento, um dos equipamentos reservas foi colocado em operação. Com esse aumento do volume captado de água bruta e frente aos valores elevados das faturas de energia elétrica, o presente estudo se concentrou na análise de dados anuais operacionais, propondo, com o uso do software EPANET 2.0, o estabelecimento de possíveis cenários que possam resultar em diminuição dos valores pagos à companhia de energia elétrica. Objetivo esse que pode ser atingido através de duas alternativas: contratação de nova modalidade tarifária e/ou diminuição do número de conjuntos motobombas acionados durante o horário de ponta (com ou sem alterações da demanda contratada). As simulações demonstraram que é viável a diminuição do número de conjuntos motobombas acionados, bem como a diminuição do valor da demanda contratada para o mesmo período. Valores próximos aos $21.136,00 \mathrm{R} \$$ mês $^{-1}$ ou $253.632,00 \mathrm{R} \$$ ano $^{-1}$ podem ser alcançados com aplicação de simples medidas operacionais/contratuais.

Palavras-chave: sistemas de abastecimento de água, estações elevatórias de água, modalidades tarifárias.
\end{abstract}

This paper aims to evaluate the economic and operational situation in a raw water lift station, wich serves two big southern brazilian cities, as provided in the normative resolution $n^{\circ} 414$, from september, the ninth, 2010, according to ANEEL. The facility is composed of five motor-pump sets, wich are triggered according to the seasonability of the potable water consumption in the supply system. In the project setup, two motorpump sets were operational reserves and, therefore, even three machines were actionated in parallel. Since 2016, because of a higher flow operational need available to the supply system, one of the stand-by equipment was put in operation. With the increase of raw water captured volume and the high electric power bills values, the focus os this research is the analysis of the operational annual data, using the EPANET 2.0 software, and proposes the establishment of possible scenarios that may result in decrease of electric power services value. This objective can be reached through two alternatives: hiring a new type of fee and/or reducing the motor-pump sets actionated during the high peak period (with or without contracted demand alteration). The simulations demonstrate that the decrease os the actionated motor-pump sets is feasible, as well as the contracted demand decrease for the same period. By means of simple operational/contractual measures, values close to $\mathrm{R} \$ 21.136,00$ by month or $\mathrm{R} \$ 253.632,00$ in an year may be reached.

Keywords: supply systems, water lift stations, fee types.

\section{INTRODUÇÃO}

O crescimento constante do número de habitantes nos centros urbanos é resultado do natural aumento populacional, também chamado de crescimento vegetativo, e, principalmente, do êxodo rural, fenômeno social bem conhecido, ainda presente na sociedade brasileira e que se intensificou na segunda metade do século XX. No Brasil, segundo dados do censo 2000 [8], foi evidenciada uma diminuição da população rural, com a taxa de urbanização passando de 75,59 \%, 
em 1991, para 81,23\%, em 2000, e, de acordo com dados do censo 2010 [9], neste ano o indicador chegou aos $84,36 \%$. Os municípios de mais de 100.000 habitantes, que possuíam 70,8 milhões de pessoas em 1991, passaram para 86,5 milhões em 2000. Já os municípios de mais de 500.000 habitantes, que contavam com 38,8 milhões de habitantes, chegaram aos valores de 46,9 milhões em 2000.

A crescente demanda por abastecimento de água nos grandes centros urbanos, decorrente dessa dinâmica populacional, acarreta, como exemplo da questão de insumos diretos, numa maior retirada de água bruta dos mananciais, bem como numa maior quantidade necessária de produtos químicos para tratamento dessa água, tornando-a potável para posterior distribuição. Na questão de insumos indiretos, a energia elétrica é um fator que merece enorme atenção, visto que as tarifas cobradas pelas concessionárias possuem valores relativamente altos e que estão sofrendo seguidos reajustes definitivos ou temporários, sendo esse último em função, basicamente, dos níveis dos reservatórios de água dos sistemas hidroelétricos que estabelecem o acionamento de um maior número de usinas termoelétricas.

Gomes (2005) [7] salienta que, apesar dos custos de implantação serem da ordem dos milhares de reais, em regra geral, os custos operacionais em estações elevatórias de água e/ou esgoto são os mais destacados. Além disso, nos últimos anos, é notável a elevação da parcela referente aos custos operacionais em virtude do aumento dos gastos energéticos associados. $\mathrm{O}$ autor destaca que esses custos vêm crescendo pois, subsídios anteriores fornecidos, principalmente nas tarifas de energia elétrica, não estão mais sendo aplicados pelo poder público, elevando-se consideravelmente os custos energéticos das empresas de saneamento. Salienta-se que os custos energéticos, em muitas companhias, representam o segundo item das despesas de exploração, ficando atrás apenas dos gastos com folha de pagamento.

Sendo assim, este artigo tem como objetivo avaliar a situação econômico-operacional atual de uma estação elevatória de água bruta e propor cenários, com o uso do software EPANET 2.0 [6], que resultem em diminuição dos valores pagos à companhia de distribuição de energia elétrica, através da contratação de nova modalidade tarifária e/ou diminuição do número de conjuntos motobombas acionados durante o horário de ponta (com ou sem alterações da demanda contratada). A instalação em estudo faz parte de um sistema integrado de abastecimento de água tratada para dois grandes municípios do estado do Rio Grande do Sul (Alvorada e Viamão), que atende aproximadamente 440.000 (quatrocentos e quarenta mil) usuários. A análise das modalidades tarifárias será realizada frente ao estabelecido na resolução normativa ${ }^{\circ} 414$, de 09 de setembro de 2010, da ANEEL [2].

\section{FUNDAMENTAÇÃO TEÓRICA}

\subsection{FORNECIMENTO DE ENERGIA ELÉTRICA}

A ANEEL é a agência reguladora no Brasil que realiza a normatização para a classificação dos consumidores de energia elétrica em classes e grupos tarifários, bem como determina a maneira como as cobranças serão efetuadas, através das modalidades tarifárias.

\subsubsection{DEFINIÇÕES INICIAIS}

A resolução normativa $n^{\circ} 414$, de 09 de setembro de 2010, da ANEEL [2], define todos os critérios utilizados no estabelecimento do enquadramento tarifário dos consumidores. Para um pleno entendimento da forma como são estabelecidos os pagamentos referentes à energia elétrica, é necessário, primeiramente, que sejam detalhados alguns conceitos iniciais, aplicáveis objetivamente à instalação em análise, e retirados da referida resolução, excetuando-se o que explicitamente estabelecido.

No Artigo $2^{\circ}$, parte XXXVI, define-se fatura, como

um documento comercial que apresenta a quantia monetária total que deve ser paga pelo consumidor à distribuidora, em função do fornecimento de energia 
elétrica, da conexão e uso do sistema ou da prestação de serviços, devendo especificar claramente os serviços fornecidos, a respectiva quantidade, tarifa e período de faturamento de modo a possibilitar ao consumidor o acompanhamento de seu consumo mensal [2, p. 4].

Já a demanda é a média das potências elétricas ativas ou reativas, solicitadas ao sistema elétrico "pela parcela da carga instalada em operação na unidade consumidora, durante um intervalo de tempo especificado, expressa em quilowatts $(\mathrm{kW})$ e quilovolt-ampère-reativo (kvar), respectivamente" [2, p. 3]. Segundo Carvalho (2017) [4], o intervalo adotado pelas concessionárias de energia elétrica é definido pelo DNAEE (Departamento Nacional de Água e Energia Elétrica) e medido através de aparelho integrador, em intervalos de 15 minutos. A demanda contratada é aquela de potência ativa que deve ser obrigatória e continuamente disponibilizada pela distribuidora, no ponto de entrega, conforme valor e período de vigência fixados em contrato, "e que deve ser integralmente paga, seja ou não utilizada durante o período de faturamento, expressa em quilowatts (kW)" [2, p. 3]. A demanda de ultrapassagem, por outro lado, é a parcela que ultrapassou o valor da demanda contratada, sendo expressa em quilowatts $(\mathrm{kW})[4]$.

A ANEEL também define o horário de ponta e o horário fora de ponta. O primeiro é o período de 3 (três) horas diárias consecutivas definidas pela distribuidora, considerando a curva de carga de seu sistema elétrico, aprovado pela ANEEL para toda a área de concessão, com exceção feita aos sábados, domingos, terça-feira de carnaval, sexta-feira da Paixão, Corpus Christi, e os feriados nacionais [2]. Já o horário fora de ponta é o período composto pelas horas diárias consecutivas e complementares àquelas definidas no horário de ponta [2]. Há ainda o período úmido, que compreende 5 (cinco) ciclos de faturamento consecutivos, referentes aos meses de dezembro de um ano a abril do ano seguinte [2], e o período seco, que são 7 (sete) ciclos de faturamentos consecutivos, referentes aos meses de maio a novembro [2].

A ANEEL (2010) [2] também estabelece a tarifa, um valor monetário fixado em R\$ (Reais), por unidade de energia elétrica ativa ou da demanda de potência ativa, que forma a base para a definição do preço a ser pago pelo consumidor e explicitado na fatura de energia elétrica. Ela se divide em:

- tarifa de energia (TE), "valor monetário unitário determinado pela ANEEL, em R $\$ / M W h$, utilizado para efetuar o faturamento mensal referente ao consumo de energia" [2, p. 10];

- tarifa de uso do sistema de distribuição (TUSD), "valor monetário (...), em R $\$ / M W h$ ou em $\mathrm{R} \$ / \mathrm{kW}$, utilizado para efetuar o faturamento mensal de usuários do sistema de distribuição de energia elétrica pelo uso do sistema" [2, p. 10];

- e tarifa binômia de fornecimento, "aquela que é constituída por valores monetários aplicáveis ao consumo de energia elétrica ativa e à demanda faturável" [2, p. 10].

A partir do ano de 2015, através da resolução normativa $\mathrm{n}^{\circ}$ 547, de 16 de abril de 2013, foi estabelecido um acréscimo no valor da energia elétrica, devido à condição de sua geração no país, sendo esse valor repassado ao consumidor final. Esse acréscimo reflete os custos operacionais momentâneos de produção da energia elétrica e é fortemente definido em função do maior ou menor uso de fontes termoelétricas. As Bandeiras Tarifárias são faturadas por meio das contas de energia e, dessa forma, todos os consumidores das distribuidoras pagam o mesmo valor, proporcional ao seu consumo, não importando qual é a sua classe de consumo. A lógica do sistema se define por cores, onde a variação dessas vai desde a bandeira verde, que representa a condição de não necessidade de pagamento de adicionais de energia elétrica, passando pela amarela (R \$ 1,00 por $100 \mathrm{kWh}$, ou suas frações) e pela vermelha-patamar I (R \$ 3,00 por 100 $\mathrm{kWh}$, ou suas frações), até gerar a condição de vermelha-patamar II, sendo essa a de maior custo ao consumidor (5,00 por $100 \mathrm{kWh}$, ou suas frações) [3].

\subsubsection{GRUPOS TARIFÁRIOS}

Até o ano de 1981, as instalações de alta tensão no Brasil eram faturadas sem diferenciação com relação ao período do ano (seco ou úmido) ou à hora do dia (ponta ou fora de ponta). Entre 
os anos 1980 e 1981 foi realizado um estudo, que resultou na subsidiação da decisão política de aplicação de tarifas diferenciadas para os consumidores conectados em Alta Tensão [1].

A partir de 1982, com a concentração de cargas existentes no período entre 17h30min e 20h30min, o DNAEE implantou a estrutura tarifária horo-sazonal. Com isso, fica estabelecido um agrupamento dos consumidores em função do nível de tensão abastecida e, consequentemente, da demanda necessária. No Brasil, surgiram dois grupos tarifários: Grupo A (Alta tensão) e Grupo B (Baixa tensão) [4]. Dando ênfase ao presente artigo, limita-se a conceituação do Grupo A de acordo com a resolução normativa $\mathrm{n}^{\circ} 414$, de 09 de setembro de 2010:

Grupo A: composto de unidades consumidoras com fornecimento em tensão igual ou superior a $2,3 \mathrm{kV},[\ldots]$, caracterizado pela tarifa binômia. É subdividido nos seguintes subgrupos:

a) subgrupo $\mathrm{A} 1$ - tensão de fornecimento igual ou superior a $230 \mathrm{kV}$;

b) subgrupo $\mathrm{A} 2$ - tensão de fornecimento de $88 \mathrm{kV}$ a $138 \mathrm{kV}$;

c) subgrupo A3 - tensão de fornecimento de $69 \mathrm{kV}$;

d) subgrupo $\mathrm{A} 3 \mathrm{a}$ - tensão de fornecimento de $30 \mathrm{kV}$ a $44 \mathrm{kV}$;

e) subgrupo A4 - tensão de fornecimento de $2,3 \mathrm{kV}$ a $25 \mathrm{kV}$;

f) subgrupo AS - tensão de fornecimento inferior a $2,3 \mathrm{kV}$, a partir de sistema

subterrâneo de distribuição [2, p. 4-5].

\subsubsection{CLASSE SERVIÇO PÚBLICO}

"As unidades consumidoras classificadas na subclasse água, esgoto e saneamento, conforme disposições do Decreto $n^{\circ} 7.891$, de 2013, tem direito ao benefício tarifário de redução nas tarifas aplicáveis [...]" [2, p. 48]. A instalação em estudo se enquadra no grupo A, subgrupo A4. Dessa maneira, os percentuais de descontos são de: $15 \%$ para TUSD $\left(\mathrm{R} \$ \mathrm{~kW}^{-1} ; \mathrm{R} \$ \mathrm{MWh}^{-1}\right) \mathrm{e}$ igualmente $15 \%$ para TE $\left(\mathrm{R} \$ \mathrm{MWh}^{-1}\right)$.

\subsubsection{MODALIDADES TARIFÁRIAS}

Conjunto de tarifas aplicáveis aos componentes de consumo de energia elétrica e demanda de potência ativas. Para o presente artigo, limita-se apenas a conceituação das modalidades tarifárias horárias verde e azul de acordo com a resolução normativa $\mathrm{n}^{\circ}$ 414, de 09 de setembro de 2010:

a) modalidade tarifária horária verde: é aplicada às unidades consumidoras do grupo A, e "caracterizada por tarifas diferenciadas de consumo de energia elétrica, de acordo com as horas de utilização do dia, assim como de uma única tarifa de demanda de potência" [2, p. 6].

A modalidade tarifária horária verde é aplicada considerando-se: (I) a tarifa única para a demanda de potência $(\mathrm{R} \$ / \mathrm{kW})$; e (II) para o consumo de energia (MWh):

a) uma tarifa para o posto tarifário ponta em período úmido ( $\mathrm{R} \$ \mathrm{MWh})$;

b) uma tarifa para o posto tarifário fora de ponta em período úmido $(\mathrm{R} \$ / \mathrm{MWh})$;

c) uma tarifa para o posto tarifário de ponta em período seco $(\mathrm{R} \$ / \mathrm{MWh})$; e

d) uma tarifa para o posto tarifário fora de ponta em período seco (R\$/MWh)" [2, p. 53].

b) modalidade tarifária horária azul: é aplicada às unidades consumidoras do grupo A, e "caracterizada por tarifas diferenciadas de consumo de energia elétrica e de demanda de potência, de acordo com as horas de utilização do dia" $[2$, p. 6].

A modalidade tarifária horária azul é aplicada considerando-se: (I) para a demanda de potência $(\mathrm{kW})$, “(a) uma tarifa para o posto tarifário ponta $(\mathrm{R} \$ / \mathrm{kW})$, e (b) uma tarifa para o posto tarifário fora de ponta $(\mathrm{R} \$ / \mathrm{kW})$ ”; e (II) para o consumo de energia $(\mathrm{MWh})$ : 
a) uma tarifa para o posto tarifário ponta em período úmido (R $\$ / \mathrm{MWh})$;

b) uma tarifa para o posto tarifário fora de ponta em período úmido (R $\$ / M W h)$;

c) uma tarifa para o posto tarifário ponta em período seco $(\mathrm{R} \$ / \mathrm{MWh})$; e

d) uma tarifa para o posto tarifário fora de ponta em período seco $(\mathrm{R} \$ / \mathrm{MWh})$ "

[2, p. 52].

\subsubsection{ENQUADRAMENTO TARIFÁRIO}

A resolução normativa $n^{\circ} 414$, de 09 de setembro de 2010, no seu artigo número 57 [2], define os enquadramentos tarifários a serem aplicados nas unidades consumidoras em função das modalidades tarifárias. Sequencialmente, são apresentados os enquadramentos utilizados nos sistemas de abastecimento de água, dispensando de apresentação àqueles destinados a outras classificações, tais como: residencial, rural e etc. Assim, limitando-se ao que interessa a este artigo, as unidades consumidoras devem ser enquadradas conforme os seguintes critérios, com ênfase objetiva à instalação em análise:

$\S 1^{\circ}$ Pertencentes ao grupo A:

II - na modalidade tarifária horária azul ou verde, de acordo com a opção do consumidor, aquelas com tensão de fornecimento inferior a $69 \mathrm{kV}$ e demanda contratada igual ou superior a $300 \mathrm{~kW}[\ldots][2$, p. 53].

\section{MATERIAL E MÉTODOS}

\subsection{APRESENTAÇÃO DO OBJETO DE ESTUDO}

Neste trabalho é proposta a realização de cenários, com o uso do software EPANET 2.0 [6], que possam resultar em diminuição dos valores pagos à companhia de distribuição de energia elétrica através, basicamente, de duas alternativas: contratação de nova modalidade tarifária e/ou diminuição do número de conjuntos motobombas acionados durante o horário de ponta (com ou sem alterações da demanda contratada). Essa instalação é existente, está em operação e pertence a um sistema de abastecimento de água de duas grandes cidades. A estação elevatória de água bruta - EBAB-01 - está localizada no município de Alvorada e tem como objetivo a adução até à estação de tratamento de água tratada - ETA - dessa cidade. A estação atende também, com água bruta para posterior tratamento, o município de Viamão, praticamente em sua totalidade (90\%). Segundo dados do censo IBGE (2017) [10], a população estimada para a cidade de Alvorada no ano de 2017 é de, aproximadamente, 208.000 pessoas [11]. Já para o município de Viamão, o número de habitantes obtidos da mesma fonte de pesquisa está estimado em, aproximadamente, 253.000 [11].

O projeto inicial da elevatória de água bruta foi concebido no início da década de 1970, previu a execução de uma linha adutora no diâmetro de $600 \mathrm{~mm}$ e a instalação de dois conjuntos motobombas, sendo um operando e outro reserva. No final da década de 1970, ocorreu a ampliação da elevatória com a implantação de uma segunda adutora de $600 \mathrm{~mm}$ e a instalação de mais um grupo, resultando, portanto, em dois conjuntos operantes e um reserva. Ao final de década de 1990, foi implantada a terceira adutora de $600 \mathrm{~mm}$, quando mais dois equipamentos foram instalados, ficando três operando e dois reservas. Até o ano de 2015, a estação elevatória estava operando com vazões máximas de $1300 \mathrm{~L} / \mathrm{s}$, com três equipamentos acionados em paralelo, valor já considerado insuficiente para atender a demanda do sistema em situações sazonais críticas. Em janeiro de 2016, por uma necessidade de maior vazão de água disponibilizada ao sistema, mais um grupo foi acionado de maneira paralela, resultando em quatro equipamentos operando e um reserva, sendo que, dessa vez, chegou-se em vazões de até 1500 L/s. Na ETA, a reservação é realizada via reservatórios de mesmas cotas e níveis máximos de água, que totalizam $16.000 \mathrm{~m}^{3}$ de água tratada armazenada quando o nível está em $100 \%$. Não existe macromedição na saída da ETA, apenas na entrada de água bruta. O sistema em estudo é ilustrado conforme a Figura 1. 


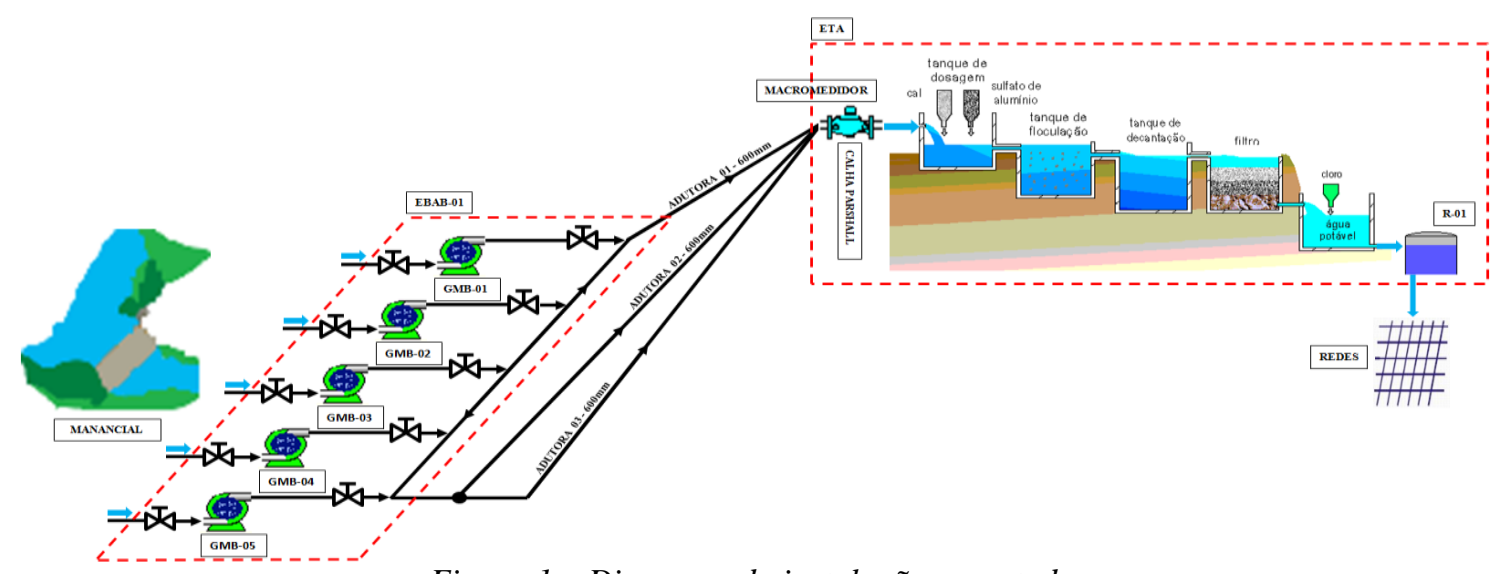

Figura 1 - Diagrama da instalação em estudo.

\subsection{COMPILAÇÃO E ANÁLISE DOS DADOS}

Como maneira de avaliação das possíveis alterações das condições operacionais da instalação visando economia monetária, foi realizada a compilação do histórico anual horário (junho de 2017 a maio de 2018, com 24 medições diárias, 365 dias no ano) da vazão dos conjuntos motobombas e dos níveis de reservação dos reservatórios da ETA, obtidos através de: calha Parshall e medidor de vazão do tipo ultrassônico, localizado na entrada da ETA, o qual contempla a vazão de todos os conjuntos acionados na EBAB-01 e, portanto, das três adutoras; e de medições realizadas por um medidor de nível com sensor do tipo hidrostático, localizado na adutora de saída por gravidade dos reservatórios. Como os reservatórios são vaso-comunicantes, o nível indicado é representativo de todos eles.

Com a compilação dos dados históricos operacionais, foi realizada uma análise, mês a mês, de maneira a se chegar ao momento considerado como o mais crítico ao abastecimento. Isso foi definido a partir dos seguintes critérios: mês que teve a maior produção média diária de água; ao mesmo tempo, que teve a menor reservação média mensal de água na ETA - o que impacta, assim, em maior quantidade de água consumida pelo sistema; além disso, foi considerado que esse mês deve ser o que teve a menor reservação média mensal na ETA no início do horário de ponta e a menor reservação média mensal no final do horário de ponta. Dentro desses índices estabelecidos, o mês classificado como crítico e que será utilizado para o restante das análises é o de abril de 2018.

Após a análise mensal, essa foi estendida para a compilação de dados referentes aos dias, o que fez com que, por exemplo, todas as segundas-feiras tenham sido agrupadas e analisadas de maneira a se obter uma curva de carga do reservatório R-01 que contemple, também, as médias horárias das vazões da estação de água bruta e os grupos acionados na EBAB-01. Dentro dessa análise semanal, o dia considerado crítico ao abastecimento, em função de critérios similares aplicados à análise mensal, foi o sábado seguido pelo domingo. Como o horário de ponta, conforme a resolução da ANEEL [2], é aplicado apenas aos dias da semana, excetuando-se basicamente os sábados, domingos e os feriados nacionais, a análise foi concentrada no período de segunda-feira à sexta-feira, resultando no dia tipicamente mais crítico, a quinta-feira, que é representada na Figura 2. 


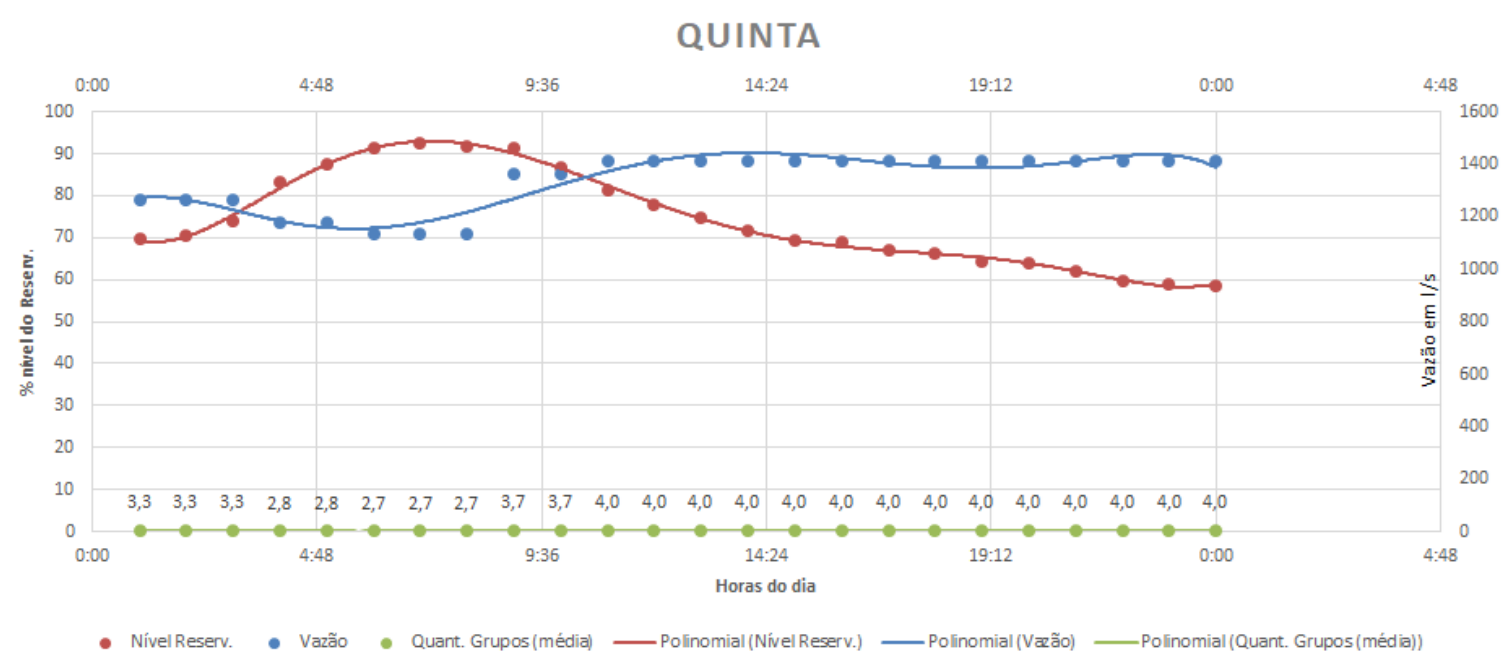

Figura 2 - Dia crítico da instalação em estudo.

Como a ETA não é macromedida em sua saída, o consumo do sistema foi estimado em relação à vazão bombeada pela EBAB-01 e à variação do nível do reservatório R-01. Dessa forma, por exemplo, se em um período de uma hora quatro equipamentos estiveram acionados na EBAB-01, o que impacta em um bombeamento real de $1.516 \mathrm{~L} / \mathrm{s}$ (aproximadamente $5.400 \mathrm{~m}^{3} \mathrm{~h}^{-1}$ ), e, nesse mesmo período, houve uma queda de $10 \%$ no nível do reservatório, que possui a capacidade de $16.000 \mathrm{~m}^{3}$, então o consumo do sistema nessa uma hora foi de $5.400 \mathrm{~m}^{3}$, referente ao bombeamento, somados aos $1.600 \mathrm{~m}^{3}$, que são relacionados à queda do nível de reservação, o que resulta em $7.000 \mathrm{~m}^{3}$ de água consumida pelas duas cidades. A partir dessas informações, foi estabelecido o padrão de consumo do dia analisado, as quintas-feiras de abril de 2018, que está representado na Figura 3.

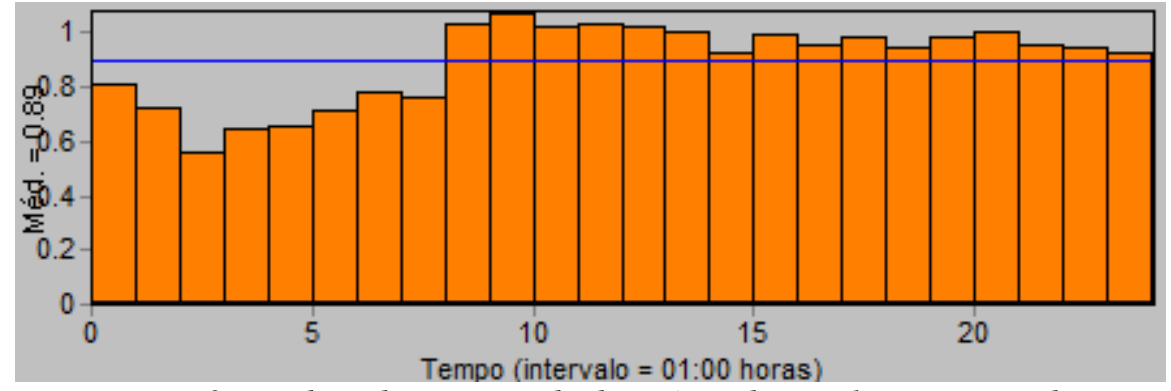

Figura 3 - Padrão de consumo do dia crítico da instalação em estudo.

Com relação ao enquadramento tarifário, a instalação em estudo pertence à classe serviço público (água, esgoto e saneamento), grupo A e subgrupo A4, sendo que ela está classificada na modalidade tarifária horária azul, a qual tem como característica a possibilidade de uma demanda contratada para o horário de ponta e outra para o horário fora de ponta. Apesar de a instalação estar enquadrada na modalidade tarifária horária azul, a demanda contratada no horário de ponta é igual à do horário fora de ponta: $2.150 \mathrm{~kW}$. A Figura 4 demonstra as tarifas praticadas pela distribuidora de energia para a demanda e a energia. 


\begin{tabular}{|c|c|c|c|c|c|c|c|}
\hline & & & $\begin{array}{c}\text { A1 } \\
(230 \mathrm{kV})\end{array}$ & $\begin{array}{c}\text { A2 } \\
(138 \mathrm{kV})\end{array}$ & $\begin{array}{c}\text { A3 } \\
(69 \mathrm{kV})\end{array}$ & $\begin{array}{c}\text { A4 } \\
(13,8 / 25 \mathrm{kV})\end{array}$ & $\begin{array}{c}\text { AS } \\
(220 / 217 \mathrm{~V})\end{array}$ \\
\hline \multirow{4}{*}{$\begin{array}{l}\text { Modalidade Tarifária } \\
\text { Horária Azul }\end{array}$} & Demanda Ponta & $\mathrm{R} \$ \mathrm{~kW}$ & 6,07 & 17,55 & 17,09 & 41,94 & 54,59 \\
\hline & Demanda Fora Ponta & $\mathrm{R} \$ \mathrm{~kW}$ & 6,19 & 14,76 & 10,99 & 20,21 & 15,83 \\
\hline & Energia Ponta & $\mathrm{R} \$ / \mathrm{kWh}$ & 0,446810 & 0,455660 & 0,456830 & 0,466200 & 0,482980 \\
\hline & Energia Fora Ponta & $\mathrm{R} \$ \mathrm{kWh}$ & 0,301090 & 0,309940 & 0,311110 & 0,320480 & 0,337260 \\
\hline & & & $\begin{array}{c}\mathrm{A} 4 \\
(13,8 / 25 \mathrm{kV}) \\
\end{array}$ & $\begin{array}{c}\text { AS } \\
(220 / 217 \mathrm{~V}) \\
\end{array}$ & & & \\
\hline \multirow{3}{*}{$\begin{array}{l}\text { Modalidade Tarifária } \\
\text { Horária Verde }\end{array}$} & Demanda & $\mathrm{R} \$ / \mathrm{kW}$ & 20,21 & 15,83 & & & \\
\hline & Energia Ponta & $\mathrm{R} \$ / \mathrm{kWh}$ & 1,483610 & 1,807560 & & & \\
\hline & Energia Fora Ponta & $\mathrm{R} \$ \mathrm{kWh}$ & 0,320480 & 0,332760 & & & \\
\hline
\end{tabular}

Figura 4 - Tarifas do Grupo A, vigentes a partir de 21/12/2017, em R\$ sem impostos [5].

\subsection{DEFINIÇÃO DOS POSSÍVEIS CENÁRIOS}

Foi construído um modelo, no software EPANET 2.0, que representa o funcionamento de até quatro equipamentos em paralelo. Os dados referentes às vazões, pressões e grandezas elétricas foram obtidos em campo e serviram para calibrar o modelo gerado no software. Foi estabelecido o método de Hazen-Williams para o cálculo das perdas de carga. Realizando o comparativo entre as medições obtidas no campo e as geradas pela simulação, a maior diferença entre a vazão real e a simulada foi de - $0,19 \%$ e, com relação à pressão, a maior diferença foi de $-1,88 \%$, o que é representativo de um modelo relativamente bem calibrado. A proposta é realizar simulações de maneira a se verificar o seguinte:

1) Possibilidade de desligamento de um ou mais conjuntos motobombas na EBAB-01 durante o horário de ponta (18h00min às $21 \mathrm{~h} 00 \mathrm{~min}$ - aplicável ao período fora do horário de verão brasileiro), mantendo os valores das demandas contratadas no horário de ponta e fora de ponta. Para realizar essa simulação, será aplicado o padrão de consumo definido na Figura 3, assumido que o nível do reservatório R-01 iniciará o dia mais crítico (quintas-feiras) às 00h00min com $40 \%$ de reservação, e que deverá atingir, no mínimo, o mesmo patamar às 23h59min. No horário de ponta, primeiramente, o conjunto motobomba número 4 será desacionado, permanecendo sempre acionados os de números 1 a 3 . Caso o nível do reservatório R-01 termine o dia acima dos $40 \%$, será realizada uma nova simulação desacionando mais um conjunto motobomba (número 3), e será avaliado se a reservação permanece ainda acima dos $40 \%$ às $23 \mathrm{~h} 59 \mathrm{~min}$.

2) Possibilidade de mudança da demanda contratada, sendo aplicada a mesma lógica do item “1)". Com isso, ela poderá ser diminuída para $1.750 \mathrm{~kW}$ (3 grupos acionados no horário de ponta) ou até mesmo $1.250 \mathrm{~kW}$ ( 2 grupos acionados no horário de ponta). Nesse caso, não existe mais a possibilidade de acionamento de quatro equipamentos durante o período de ponta, devido às multas aplicáveis em função das ultrapassagens de demanda contratada para o período. De acordo com o Seção II, Art. 93, da resolução normativa $n^{\circ} 414$, de 09 de setembro de 2010, da ANEEL, as multas aplicáveis são definidas como a diferença entre o valor contratado e o medido, multiplicadas por um fator de duas vezes o valor de referência equivalente às tarifas de demanda de potência aplicadas, sendo que:

quando os montantes de demanda de potência ativa ou de uso do sistema de distribuição medidos excederem em mais de 5\% (cinco por cento) os valores contratados, deve ser adicionada ao faturamento regular a cobrança pela ultrapassagem [2, p. 69].

3) Possibilidade de modificação do enquadramento tarifário da instalação (de azul para verde), mantendo-se a mesma demanda contratada na ponta e fora de ponta: $2.150 \mathrm{~kW}$. Isso irá impactar em uma grande redução sobre os valores pagos pela demanda. No entanto, os valores pagos pelo consumo da energia irão aumentar em $318 \%$ no horário de ponta, conforme figura 4 , em função dessa modalidade ser mais vantajosa, no horário de ponta, nos valores relativos à demanda e muito mais onerosa na questão do consumo. 


\section{RESULTADOS E DISCUSSÃO}

Foi realizada a primeira simulação com o desacionamento de apenas o grupo motobomba de número 4 no período de ponta, que é entre $18 \mathrm{~h} 00 \mathrm{~min}$ e $21 \mathrm{~h} 00 \mathrm{~min}$. Conforme a Figura 2, no dia crítico analisado, no período entre as $00 \mathrm{~h} 00 \mathrm{~min}$ e as $11 \mathrm{~h} 00 \mathrm{~min}$, em média, 3,1 grupos permanecem acionados na EBAB-01 e, no período entre as $11 \mathrm{~h} 00 \mathrm{~min}$ e as $23 \mathrm{~h} 59 \mathrm{~min}$, em média, 4 equipamentos permanecem ligados na mesma instalação. A reservação do R-01, em média, inicia o dia com $70 \%$ e finaliza, em média, com $60 \%$. Com a proposta de desligamento de apenas 1 conjunto motobomba no horário de ponta, o período médio de permanência de 4 grupos acionados na estação elevatória de água bruta aumentará de 13 horas para 21 horas e o de permanência de apenas 3 grupos acionados na EBAB-01 diminuirá de 11 horas para, aproximadamente, 3 horas.

A situação analisada possui uma curva de consumo de acordo com a Figura 3 e, levando em consideração que a reservação irá iniciar, em todas as simulações, com $40 \%$ às $00 \mathrm{~h} 00 \mathrm{~min}$, conforme a Figura 5A, durante a simulação, no horário aproximado de 05h30min houve transbordamento do reservatório da ETA, chegando em $20 \%$ de transbordamento às $08 \mathrm{~h} 00 \mathrm{~min}$ e às $18 \mathrm{~h} 00 \mathrm{~min}$ e, no final do dia, às $23 \mathrm{~h} 59 \mathrm{~min}$, o nível finalizou em $110 \%$. A variação do nível do R-01 dentro do horário de ponta na condição de apenas um grupo desacionado foi de $15 \%$. Esses dados são indicativos da possibilidade de desacionamento de mais um grupo motobomba na EBAB-01 no horário de ponta. Foi realizada, portanto, uma nova simulação, agora com o desacionamento dos grupos de números 4 e 3 na EBAB-01. Conforme a Figura 5B, dessa vez houve novamente o transbordamento do reservatório R-01 às $05 \mathrm{~h} 30 \mathrm{~min}$, com os níveis atingindo o patamar de $120 \%$ às $08 \mathrm{~h} 00 \mathrm{~min}$ e às $18 \mathrm{~h} 00 \mathrm{~min}$ e, o nível de reservação finalizou o dia em, aproximadamente, $83 \%$, sendo esse parâmetro acima do inicialmente estabelecido - $40 \%$. No entanto, a queda no horário de ponta foi de, aproximadamente, $42 \%$. Uma simulação com apenas um conjunto motobomba acionado no horário de ponta não é possível de ser realizada, pois a ETA não comporta o tratamento de água relativo à vazão aduzida por apenas um equipamento motobomba acionado na EBAB-01.

Nível R-01 (coluna hidrostática - pressão), com apenas 1 grupo desacionado no horário de ponta (A)

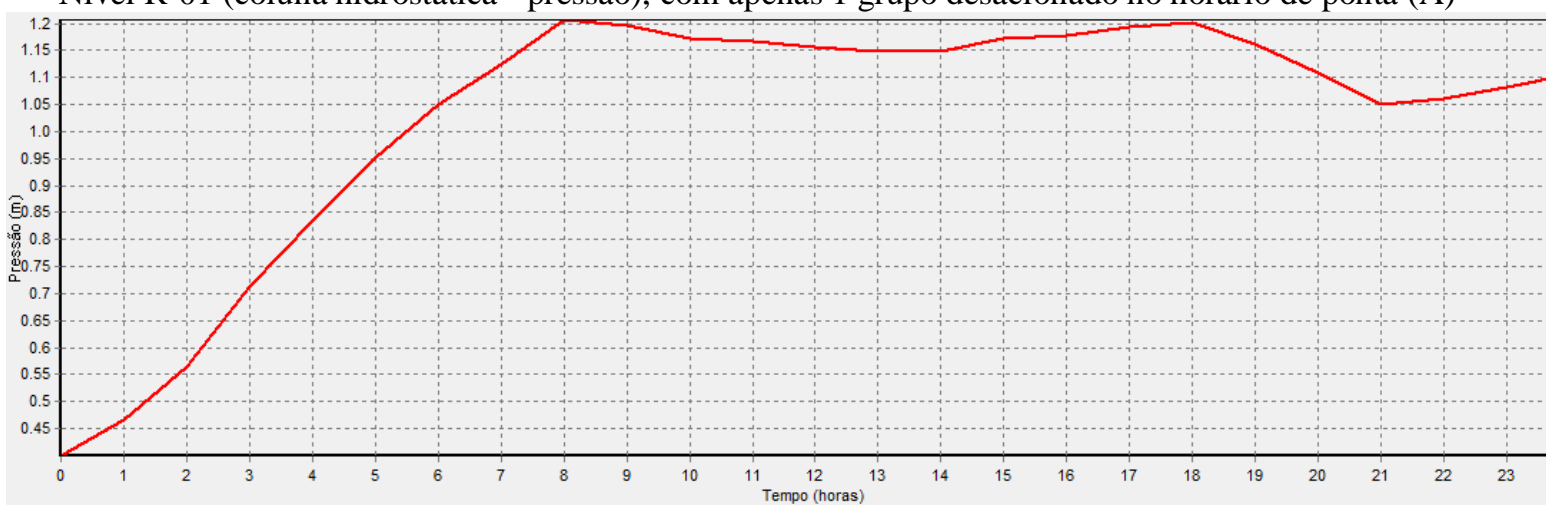

Nível R-01 (coluna hidrostática - pressão), com 2 grupos desacionados no horário de ponta (B)

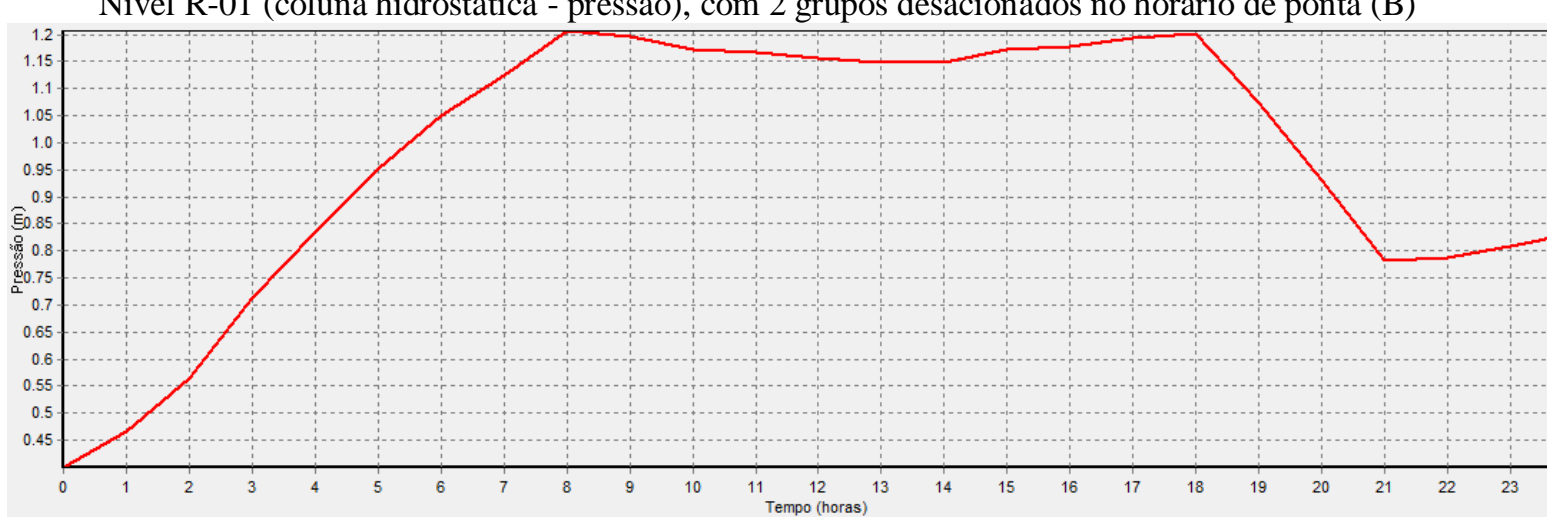

Figura 5 - Análise do desacionamento de equipamentos no horário de ponta, com 4 grupos motobombas acionados fora do horário de ponta. 
Com as simulações executadas até o momento, foi possível perceber que não é viável, por segurança operacional do sistema, uma queda de até $42 \%$ da reservação em três horas do horário de ponta, quando da permanência de apenas 2 conjuntos acionados na estação de bombeamento de água bruta. Sendo assim, a partir desse momento, as simulações foram executadas com o desligamento de apenas um conjunto motobomba no horário de ponta.

Como o nível do reservatório R-01 permanece acima dos $100 \%$ entre às $05 \mathrm{~h} 30 \mathrm{~min}$ e às 19h30min, quando 4 equipamentos permanecem acionados na EBAB-01 fora do horário de ponta (21 horas) e 3, apenas, durante as 3 horas do horário de ponta; e, levando em consideração que o dia mais crítico é o em análise, utilizando os dados da Figura 2, uma nova simulação foi gerada, onde três equipamentos $(1,2$ e 3$)$ permaneceram acionados entre às $00 \mathrm{~h} 00 \mathrm{~min}$ e às $11 \mathrm{~h} 00 \mathrm{~min}$ e, no restante do período do dia, 4 equipamentos permaneceram acionados na EBAB-01, excetuando-se o horário de ponta, que voltou a possuir 3 equipamentos acionados no sistema. Nessa nova simulação, conforme a Figura 6, a queda da reservação durante o horário de ponta foi de, aproximadamente, $15 \%$. O nível do reservatório R-01 chegou em, aproximadamente, $41 \%$ no final do horário de ponta e aos $47 \%$ às $23 \mathrm{~h} 59 \mathrm{~min}$.

Nível R-01 (coluna hidrostática - pressão), com apenas 1 grupo desacionado no horário de ponta

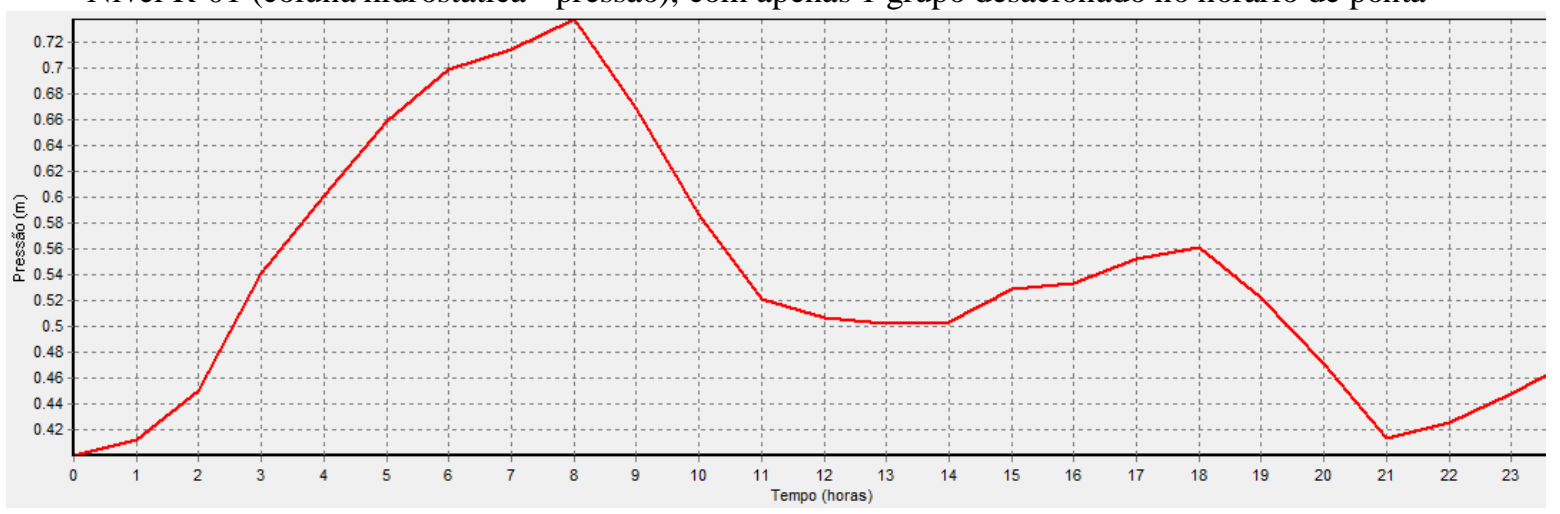

Figura 6 - Análise do desacionamento de equipamentos no horário de ponta, com sequenciamento dos grupos motobombas acionados de acordo com o dia crítico.

Com relação a análise da mudança de modalidade tarifária horária azul (atual) para verde, na Tabela 1 foi realizada uma avaliação monetária detalhada comparando os custos relativos à demanda e os custos relativos à energia. Os valores são conforme Resolução Homologatória ANEEL no. 2.361/2017 (Figura 4).

O custo de energia pago no horário fora de ponta é o mesmo para a modalidade verde e para a azul $\left(0,32048 \mathrm{R} \$ \mathrm{kWh}^{-1}\right)$, mas no horário de ponta o custo da energia paga na modalidade verde $\left(1,48361 \mathrm{R} \$ \mathrm{kWh}^{-1}\right)$ é 3,18 vezes maior que o da modalidade azul $\left(0,4662 \mathrm{R} \$ \mathrm{kWh}^{-1}\right)$. Dessa maneira, dependendo do consumo de energia elétrica, pode ser muito mais vantajoso ao usuário a aplicação da modalidade tarifária horária azul com a mesma demanda contratada para o período fora e em ponta, apesar da demanda contratada da modalidade tarifária horária azul $(41,94 \mathrm{R} \$$ $\left.\mathrm{kW}^{-1}\right)$ ser 2,08 vezes maior que a verde $\left(20,21 \mathrm{R} \$ \mathrm{~kW}^{-1}\right)$, na ponta, e igual $\left(20,21 \mathrm{R} \$ \mathrm{~kW}^{-1}\right)$ no período fora de ponta. Esse é o caso da instalação em análise, que diminuiria o custo pago em demanda contratada, no horário de ponta, de 90.171,00 R \$ mês ${ }^{-1}$ (modalidade tarifária azul, contratado $2.150 \mathrm{~kW}$ ) para 43.451,50 R\$ mês $^{-1}$ (modalidade tarifária verde, contratado 2.150 $\mathrm{kW}$ ), no entanto, com um consumo de energia no horário de ponta podendo saltar, de acordo com os valores da Tabela 1, de 64.166,00 R $\$$ mês $^{-1}$ (azul) para 204.199,00 R \$ mês ${ }^{-1}$ (verde). Dessa maneira, é totalmente desaconselhável a mudança da modalidade tarifária horária azul para a verde.

Tabela 1 - Comparativo de custos da energia elétrica, em função das alterações operacionais elou contratuais.

\begin{tabular}{lll}
\hline \multicolumn{4}{|c}{ DEMANDA } \\
\hline $\begin{array}{l}\text { Situação atual da instalação } \\
\text { Modalidade tarifária horária azul }\end{array}$ & $\begin{array}{l}\text { Avaliação de alteração da demanda } \\
\text { contratada no horário de ponta para }\end{array}$ & $\begin{array}{l}\text { Avaliação de alteração da demanda } \\
\text { contratada no horário de ponta }\end{array}$ \\
\hline
\end{tabular}




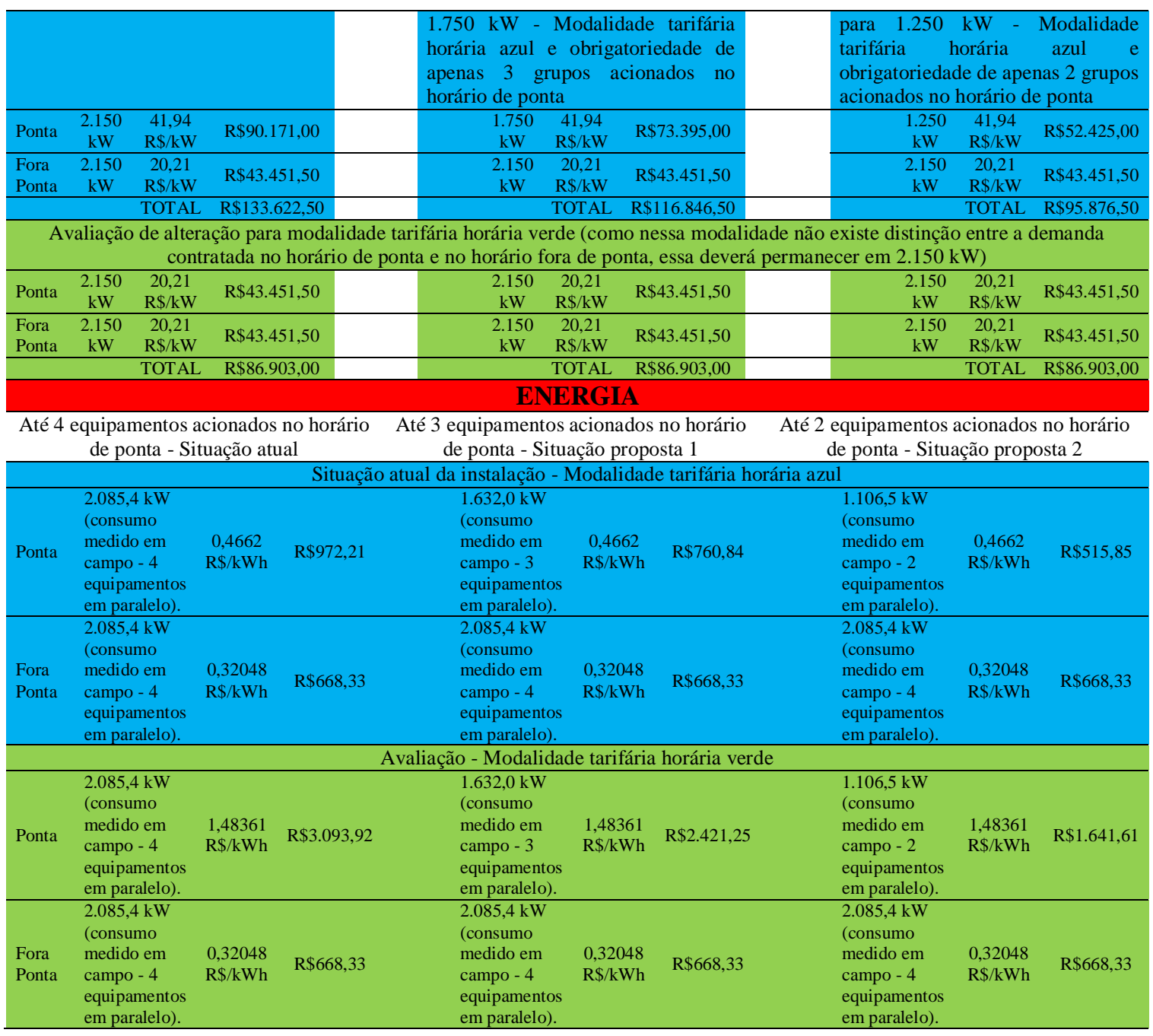

\section{CONCLUSÃO}

Nas simulações executadas foi possível identificar que a instalação permite, com uma margem muito grande de segurança operacional, o desacionamento de um conjunto motobomba durante $o$ horário de ponta. As simulações realizadas com 4 grupos motobombas acionados no horário fora de ponta (21 horas) e, 3 ou até mesmo apenas 2 acionados no horário de ponta (3 horas), revelaram que os reservatórios nem mesmo comportariam o volume de tanta água aduzida, permanecendo boa parte do dia acima das suas capacidades máximas, mesmo iniciando o dia com apenas $40 \%$ de reservação. Dessa maneira, uma nova simulação foi executada com o dia mais crítico frente ao consumo do sistema de abastecimento de água (quintas-feiras de abril de 2018), com uma análise estendida, além da curva consumo, para um sequenciamento de grupos acionados muito próximo ao real praticado no dia em análise, excetuando-se o horário de ponta, que na situação real possui, normalmente, 4 equipamentos acionados e, na situação analisada, permitirá apenas 3. Na situação descrita, a economia chega em valores próximos aos 4.360,00 R \$ mês ${ }^{-1}\left(52.320,00 \mathrm{R} \$\right.$ ano $\left.^{-1}\right)$ e o nível do reservatório R-01 permanece em $47 \%$ às $23 \mathrm{~h} 59 \mathrm{~min}$.

As análises demostraram que, em um horizonte de um ano de dados, mesmo no dia mais crítico ao consumo do sistema, que foi estabelecido como sendo as quintas-feiras do mês de maio de 2018, o reservatório R-01 inicia, em média, com aproximadamente $70 \%$ de sua capacidade às 00h00min e finaliza o dia, em média, com $60 \%$ de reservação. Na simulação executada com a curva de carga do reservatório nesse dia crítico, com o sequenciamento dos grupos acionados muito similar ao praticado no dia em análise, excetuando-se o acionamento de 4 equipamentos no horário de ponta e, assumindo que o nível de reservação no R-01 passe de $70 \%$ para $40 \%$ às 00h00min ocorreu que a reservação chegou em $47 \%$ às $23 \mathrm{~h} 59 \mathrm{~min}$. Dessa maneira, pode-se 
concluir que a demanda contratada no horário de ponta permite, com segurança operacional, uma redução de $2.150 \mathrm{~kW}$ para $1.750 \mathrm{~kW}$, onde se passaria a pagar, nesse período, um valor de 73.395,00 R \$ mês ${ }^{-1}$ frente aos 90.171,00 R\$ mês ${ }^{-1}$ pagos com a demanda atual. Por fim, é indispensável ressaltar que, com a alteração da demanda contratada de $2.150 \mathrm{~kW}$ para $1.750 \mathrm{~kW}$ no horário de ponta e a economia de valores pagos, somente pela demanda contratada, da ordem de $16.776,00 \mathrm{R} \$$ mês $^{-1}\left(201.312,00 \mathrm{R} \$\right.$ ano $\left.^{-1}\right)$ é obrigatório a realização de uma gestão muito forte quanto ao desligamento programado do $4^{\circ}$ equipamento antes da entrada no horário de ponta. Isso se deve aos valores altíssimos aplicados às ultrapassagens de demandas onde, por exemplo, se 4 equipamentos estiverem funcionando por apenas períodos ínfimos no horário de ponta, a multa por ultrapassagem de demanda chega em valores de duas vezes o preço da demanda regular, sem incidências de descontos, o que é superior aos $\mathrm{R} \$ 33.552,00$.

\section{REFERÊNCIAS BIBLIOGRÁFICAS}

1. ANEEL - Agência Nacional de Energia Elétrica. Nota Técnica n 271/2009-SRE-SRD/ANEEL, de 4 ago. 2009. Processo $\mathrm{n}^{\circ}$ 48500.004247/2009-37. Assunto: proposta de Alteração Metodológica da Estrutura Tarifária Aplicada ao Setor de Distribuição de Energia Elétrica no Brasil - 10 Parte. Disponível

<http://www2.aneel.gov.br/aplicacoes/consulta_publica/documentos/Nota\%20Técnica_271_2009Estrutura\%20Tarifária-1RA\%20(2).pdf>. Acesso em 15 jul. 2018.

2. __ Resolução Normativa $\mathrm{n}^{\circ}$ 414, de 9 de set. de 2010. Assunto: estabelece as Condições Gerais de Fornecimento de Energia Elétrica de forma atualizada e consolidada. Disponível em: <http://www.aneel.gov.br/documents/656877/14486448/bren2010414.pdf/3bd33297-26f9-4ddf-94c3f01d76d6f14a?Version=1.0>. Acesso em 15 jul. 2018.

3. _ Bandeiras tarifárias. Publicado em 24 nov. 2015 às 09:10 [última modificação: 03 nov. 2017 às 11:02]. Disponível em: 〈http://www.aneel.gov.br/bandeiras-tarifarias>. Acesso em 12 jan. 2018.

4. Carvalho JF de. Eficiência Energética e Hidráulica no Saneamento. São Paulo: All Print Editora, 2017.

5. CEEE. Tabela de Tarifas - Grupo A. Vigentes a partir de 21/12/2017, conforme Resolução Homologatória ANEEL no 2.361/2017. CEEE, s/ data. Disponível em: <http://www.ceee.com.br/pportal/ceee/Archives/Upload/Tarifas_A-2017-12_85226.pdf〉. Acesso em 5 set. 2018.

6. EPANET, Application for Modeling Drinking Water Distribution Systems. Version 2.0. EPA - United States Environmental Protection Agency, 2011.

7. Gomes HP. Eficiência Hidráulica e Energética no Saneamento - Análise Econômica de Projetos. $1^{\circ}$ Edição. Rio de Janeiro: ABES - Associação Brasileira de Engenharia Sanitária e Ambiental, 2005.

8. IBGE - Instituto Brasileiro de Geografia e Estatística. ONU e IBGE divulgam relatórios de população. Disponível em: 〈https://ww2.ibge.gov.br/home/presidencia/noticias/11122001onu.shtm〉. Acesso em 14 jul. 2018.

9. Censo demográfico 1940-2010. IBGE, Séries históricas e estatísticas, s/ data. Disponível em: <https://seriesestatisticas.ibge.gov.br/series.aspx?vcodigo=POP122〉. Acesso em 15 jul. 2018.

10. . Município Alvorada. IBGE, 2017. Disponível em: 〈https://cidades.ibge.gov.br/brasil〉. Acesso em 12 jul. 2018.

11. Município Viamão. IBGE, 2017. Disponível em: 〈https://cidades.ibge.gov.br/brasil〉. Acesso em 12 jul. 2018. 